Social Inequality and Social Mobility: Is there an Inverse Relation?

\author{
Erzsébet Bukodi \\ Department of Social Policy and Intervention, \\ Nuffield College \\ University of Oxford \\ erzsebet.bukodi@nuffield.ox.ac.uk \\ John H. Goldthorpe \\ Nuffield College \\ University of Oxford \\ John.goldthorpe@nuffield.ox.ac.uk
}

October 2018 


\title{
Social Inequality and Social Mobility: Is there an Inverse Relation?
}

\begin{abstract}
While accepting that an inverse relation of some kind exists between inequality and mobility, we begin by reviewing criticisms of recent attempts by economists to express this relation in terms of income inequality and mobility - the 'Great Gatsby Curve'. This appears to be neither empirically secure nor theoretically well-grounded. Using a newly constructed European dataset, we then aim to show that if mobility is treated in terms of social class, rather than income, an inverse relation with social inequality can be suggested that is more complex but that has a stronger empirical and a more coherent theoretical basis. Our results indicate that European countries are best seen not as displaying entirely continuous variation in their relative rates of class mobility, but rather as falling into a number of comparatively high and low fluidity groups. We offer an interpretation of these results that starts out from the proposition that within societies with a capitalist market economy, a nuclear family system and a liberal democratic polity, some limit exists to the extent to which relative mobility rates can be brought towards equality. Variation in such rates can then be understood in terms of how close nations are to this limit, and whether they are moving towards or receding from it, but with different forms of inequality impacting on their fluidity trajectories in differing ways.
\end{abstract}




\section{Introduction}

The relation between social inequality and social mobility has been discussed from a number of different standpoints. A view often taken from a broadly liberal position is that socio-political concerns over inequality are mitigated if mobility is at a high level: that is, if the extent to which more or less advantaged social positions are transmitted across generations is limited and individuals' life-chances are not closely tied to the circumstances of their birth. It is this view that would appear to underlie the fact that in countries such as the UK and the US, in which, over recent decades, social inequality has significantly widened, increasing mobility has become a prime focus of political and policy interest. Rather than any tension being recognised between inequality and mobility, what is implied is that if inequality is the problem, mobility is the solution.

Sociologists have always tended to be sceptical of this liberal position because of their awareness of the ways in which inequalities of condition can compromise equality of opportunity. However, of late the strongest challenge has come from economists. What is claimed is that a direct inverse relation can be shown between income inequality and intergenerational income mobility - the so-called 'Great Gatsby Curve' (Krueger, 2012; Corak, 2013). This is actually a best-fitting straight line drawn through a bivariate scatterplot of national societies in which a measure of mobility - the intergenerational earnings elasticity (IEE) - on the $y$-axis is set against Gini coefficients for income inequality on the x-axis. Mobility appears lower in societies where inequality is higher.

In this paper, we begin by outlining a number of criticisms of the Great Gatsby Curve (henceforth the GGC) that have emerged and that we find forceful. Our main concern, 
however, is to show that if mobility is treated in terms of social class, rather than income, and if a clear distinction is made between absolute and relative mobility rates, then a relation between relative mobility and inequality, considered more broadly than simply income inequality, can be suggested. This relation, while still generally inverse, is of a more complex kind than that expressed in the GGC, but has a more secure empirical and a more coherent theoretical basis.

\section{Criticisms of the Great Gatsby Curve}

Criticisms of the GGC have been made in regard to issues of data, measurement and theory. We review these in turn.

Data

The main data problem that arises in analyses of income mobility concerns the incomes of parents or, what is in fact most often measured, simply the earnings of fathers, which are then related to the earnings of sons. (Women are not often included in either generation). However, reliable data for fathers' earnings that can be used in this way are only available for countries with either income or tax registration systems or long-established birth cohort or panel studies within which pairs of fathers and sons can be identified. In many countries that have been included in versions of the GGC these possibilities do not exist. Sons' earnings are obtained from their responses to surveys and fathers' earnings are then 'imputed' on the basis of further 
information provided by sons on their fathers' education and/or occupation. ${ }^{1}$ The reliability of such imputation is open to serious question. The choice and the measurement of imputer variables and the particular imputation models used can lead to wide variation in estimates of earnings mobility, whether based on the IEE or otherwise (Jerrim, Choi and Simancas, 2016).

Some years before the GGC was proclaimed, Björklund and Jäntti (2009: Figure 20.1) showed, in relation to their Ginis, the estimated IEEs for a number of countries, together with 95\% confidence intervals. These intervals proved to be very small where fathers' as well as sons' earnings were actually observed, as from registration data, but very large where fathers' earnings were imputed. From Björklund and Jäntti's figure, it could not in fact be claimed that income mobility was lower in countries such as Australia, Germany and the UK than in the Nordic countries, despite their having clearly higher Ginis. These results would appear to have been unduly neglected.

\section{Measurement}

The IEE is simply the coefficient resulting from regressing sons' (log) earnings on fathers' (log) earnings. As such, it has some attraction as a descriptive statistic, showing, roughly, the proportion of earnings differences in one generation that is, on average, transmitted the next. ${ }^{2}$ However, for analytical purposes, the IEE has a major disadvantage. As a regression coefficient, it reflects not only what one might call the net intergenerational association of earnings but also any changes in the degree of inequality in earnings between the generations. Thus, as used

\footnotetext{
${ }^{1}$ While sons are likely to be able to report, fairly reliably, their fathers' occupation and educational level, they cannot be expected to recall from their childhood or adolescence - or in fact ever to have known - their fathers' earnings.

${ }^{2}$ More precisely, it shows the percentage differential in the geometric mean of sons' earnings with respect to a marginal percentage differential in fathers' earnings.
} 
in the GCC, it leads to an unfortunate confounding of the two key variables of inequality and mobility. Following the IEE, a society in which the net intergenerational association of earnings is relatively weak but in which earnings inequality has widened between the generations could appear as less mobile than a society with a stronger net association but in which earnings inequality was stable (see further Jäntti and Jenkins, 2015; Winship, 2017). A better measure of mobility would therefore be the Pearsonian correlation coefficient, $r$, which would control for intergenerational change in earnings inequality. But $r$ still shares in a further shortcoming of the IEE in that it assumes that the relation between earnings across the generations is linear, and research indicates that this is not always so - as, for example, in the Nordic countries (Bratsberg et al., 2007). If, then, the focus is on relative mobility and a 'one number' measure is required, a rank correlation, such as Spearman's rho, could be regarded as preferable (Jäntti and Jenkins, 2015). ${ }^{3}$

These considerations are important because the use of different measures of mobility can lead to very different results as regards the relation to inequality. For example, in a paper of which Corak, a leading proponent of the GGC, is in fact a co-author (Corak, Lindquist and Mazumder, 2014), it is shown that, on the basis of rho, income mobility in the US is at around the same level as in Sweden, despite these two countries being at opposite ends of the international Gini range.

3 In national studies, various other approaches to the measurement of intergenerational earnings mobility, and of income mobility more widely understood, have been developed that both control for intergenerational changes in inequality and allow for nonlinearities - for example, 'rank-rank slope' and semi-parametric and non-parametric methods. But these innovations have not, so far, been carried over into comparative studies. In a recent OECD report (2018) the IEE is routinely used as a measure of income mobility without any serious consideration of its weakness. 
Theory

Those economists who have advanced the GGC have been careful to say that the inverse relation between income inequality and mobility that is shown does not in itself demonstrate causation. But they have at the same time maintained that the GGC is consistent with economic theory that does in fact imply causation. What theory indicates (see Krueger, 2012; Corak 2013, 2015) is that if income inequality widens in one generation - as the result, say, of increasing earnings returns to human capital, and especially to education - this will lead to a greater inequality in relative mobility chances in the next generation in the following ways. On the one hand, there will be a greater inequality in the economic resources that parents have available to 'invest' in their children in order to promote their educational attainment and, in turn, their earnings prospects in the labour market; and, on the other hand, in a context of rising income inequality, there will be stronger incentives for parents to make such investments.

However, difficulties with the theory become apparent as it is developed in greater detail. It turns out that the family resources that are seen as important in furthering children's education are by no means limited to income. Resources of other kinds are repeatedly invoked, even if in an essentially ad hoc fashion. To take examples from the papers cited above, references are made to 'family connections', 'family culture' and parents' own educational attainment. The coherence of the theory is then maintained, one has to suppose, simply by the assumption that these other resources are so highly correlated with income that income can in effect stand for all. But sociological research would indicate otherwise. Parental sociocultural and specifically educational resources are correlated with economic resources, but only moderately so. And in empirical studies of children's educational attainment, different 
parental resources prove to have independent, and in turn cumulative, effects - with those of parental income being in no way predominant (Jaeger, 2007; Buis, 2013; Bukodi, Erikson and Goldthorpe, 2014; Bukodi and Goldthorpe, 2018).

Finally, it may be noted here that even setting aside all of these problems that arise with the GCC, what is, at this writing, the latest version of it to be produced (OECD, 2018: 196, Figure 4.9) is not in itself all that convincing. The inverse slope revealed is strongly dependent on the 'emerging economies' included in the scatterplot; and if, as in Figure 1, these are excluded, the slope is much weakened. The Nordic countries are distinctive in having low inequality and high mobility but with the remaining countries there is little indication of the GGC. There would then seem opportunity for some alternative approach to understanding the relation between inequality and mobility, and this we now seek to provide, focusing on the European context. ${ }^{4}$

\footnotetext{
${ }^{4}$ It may also be noted that it is questionable how well the GGC can serve to predict changes in income mobility from changes in income inequality. Thus, in the case of the US, while some analysts (e.g. Davis and Mazumder, 2017) have claimed to show that with rising income inequality after 1980 relative income mobility has fallen - as Krueger (2012) would expect from the GGC - others, notably Chetty et al. (2014), maintain that, contrary to Krueger's expectations, the net association between parents and children's incomes has remained remarkably stable over recent decades. And Hout (2018) finds no significant change in relative mobility as measured in terms of socioeconomic status over the period 1994-2016.
} 
FIGURE 1: Intergenerational earnings mobility and income inequality (a) (b)

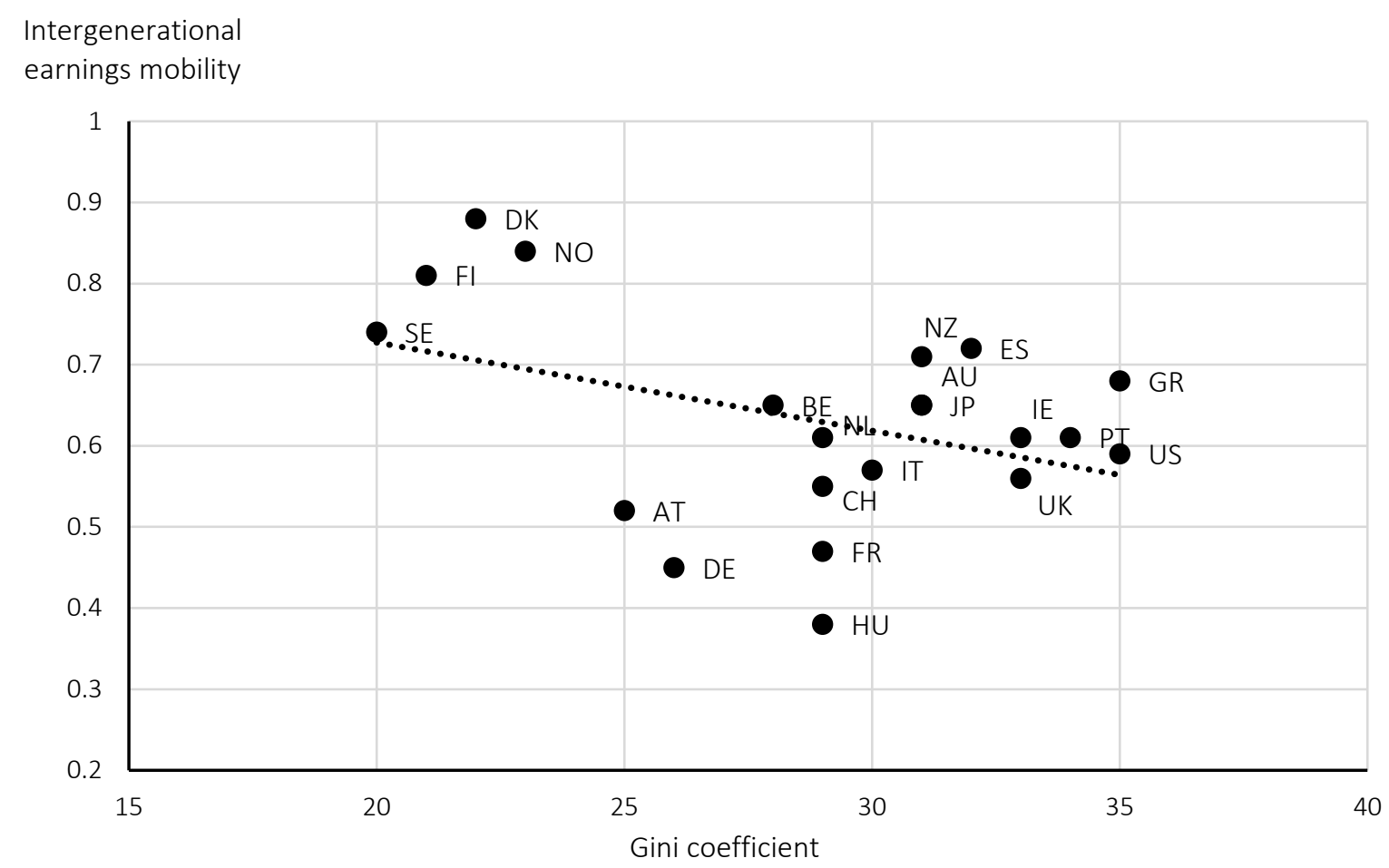

Notes:

(a) Earnings mobility is proxied by 1 minus the intergenerational earnings elasticity.

(b) UK: United Kingdom; NO: Norway; FR: France; SE: Sweden; FI: Finland; DK: Denmark; IE: Ireland; NL: Netherlands; CH: Switzerland; BE: Belgium; AT: Austria; DE: Germany; IT: Italy; GR: Greece; ES: Spain; PT: Portugal; HU: Hungary; US: United States; AU: Australia; JP: Japan; NZ: New Zealand

\section{Inequality and Social Class Mobility}

Sociologists differ from economists in preferring to study mobility between social strata, conceptualised in one way or another, rather than between levels in the income distribution. Of late, interest has centred on mobility between social classes, defined in terms of the social relations in which individuals are involved in labour markets and production units or, in other words, in terms of their employment relations. This approach to the conceptualisation of social class is now in fact reflected in the social classifications used in the official statistics of several 
European countries and, most importantly for present purposes, directly informs the European Socio-economic Classification ( $\mathrm{ESeC}$ ) that provides the basis for the mobility analyses that we will present. ${ }^{5}$

The main argument for studying mobility on the basis of class rather than of income is that, because class can be shown to capture income security, income stability and income prospects as well as current income level (Bukodi and Goldthorpe, 2018), class mobility more fully reflects the extent to which economic advantage and disadvantage are intergenerationally transmitted. And there is confirmatory evidence in this regard in that the intergenerational association between individuals' class positions appears generally stronger than that between their income levels (Goldthorpe, 2013; Erikson, 2016).

In pursuing the question of the relation between inequality and class mobility, we draw on a new dataset derived from the European Social Survey (ESS) that allows us to produce class mobility tables for 30 European countries. The data come from the first five waves of the ESS, carried out between 2002 and 2010, which involved face-to-face interviews with individuals in probability samples drawn from the adult population of each country. The tables are constructed by cross-classifying the class positions of respondents aged 25-64 at time of interview with the class positions of their parents at respondents' age 14 according to the 7class version of ESeC that is shown in Table $1 .{ }^{6}$ In line with the analyses that are incorporated into the GGC, we concentrate here on the tables for men.

\footnotetext{
${ }^{5} \mathrm{ESeC}$ was developed with the idea that it would become the official EU social classification. Eurostat declined this possibility but ESeC is now widely used in academic research and indeed also by some EU bodies, such as Eurofound. For full details of the classification, see Rose and Harrison (2010).

${ }^{6}$ Where parents held different class positions, the 'dominance' method (Erikson, 1984) was applied.
} 
TABLE 1: The European Socio-economic Classification (ESeC)

\begin{tabular}{cl}
\hline Class & \\
\hline Class 1 & Large employers, higher grade professionals and managers \\
Class 2 & Lower grade professionals and managers, higher grade technicians and supervisors \\
Class 3 & Intermediate occupations ${ }^{(a)}$ \\
Class 4 & Small employers and own account workers \\
Class 5 & Lower supervisors and lower technicians \\
Class 6 & Lower services, sales, clerical and technical occupations \\
Class 7 & Routine occupations \\
\hline
\end{tabular}

Note:

(a) Intermediate occupations comprise mainly ancillary professional and administrative employees.

In analysing these tables, our focus is, to repeat, on relative rather than absolute mobility rates: that is to say, we focus on mobility chances as expressed in the associations existing between the class positions of men and of their parents when considered net of all changes in class structure as these may be reflected in the marginal distributions of the tables. This is to parallel that aspect of mobility that, we would suppose, the GGC aims to capture - even if inadequately insofar as the IEE is used rather than measures such as $r$ and rho that control for intergenerational differences in the distribution of incomes.

\section{Models and Results}

Following now standard sociological practice, we analyse relative class mobility on the basis of the two following models. 
(1) The loglinear common association (CA) model, proposing a common pattern of association between class origins and destinations from one country to another:

$$
\log F_{i j k}=\mu+\lambda_{i}^{O}+\lambda_{j}^{D}+\lambda_{k}^{C}+\lambda_{i k}^{O C}+\lambda_{j k}^{D C}+\lambda_{i j}^{O D}
$$

where $\mathrm{F}_{\mathrm{ijk}}$ is the expected frequency in a cell of a three-way table of class origins (O) by class destinations (D) by country $(C), \mu$ is a scale factor, and the following terms capture the marginal effects of origins, destinations and countries and also the three possible two-way associations. Under this model, all the log odds ratios defining the origins-destinations associations - there are 441 of them in $7 \times 7$ mobility tables - are identical from one country to another.

(2) The logmultiplicative uniform difference (UNIDIFF) model (Erikson and Goldthorpe, 1992; cf. Xie, 1992), proposing a uniform difference in the strength of the association between class origins and destinations from one country to another:

$$
\log F_{i j k}=\mu+\lambda_{i}^{O}+\lambda_{j}^{D}+\lambda_{k}^{C}+\lambda_{i k}^{O C}+\lambda_{j k}^{D C}+\beta_{k} X_{i j}^{O D}
$$

where in the $\beta_{\mathrm{k}} \mathrm{X}_{\mathrm{ij}}^{\mathrm{OD}}$ term that is added to the CA model $\mathrm{X}_{\mathrm{ij}}^{\mathrm{OD}}$ represents the general pattern of the origin-destination association across the countries involved and $\beta_{\mathrm{k}}$ the relative strength of this association that is specific to a particular country. This model thus allows us to test for the possibility that from one country to another the log odds ratios defining the origin-destination associations are all greater or less by some common, multiplicative factor, thus implying greater or less equality in relative rates or a systematic difference in the degree of social fluidity within countries' class structures.

We proceed by fitting the CA and the UNIDIFF models to each pair of the 30 countries in our data set. One way of summarising the results obtained is shown in Figure 2. This figure is arrived at as follows. First, the average of all the UNIDIFF parameters returned from the 
pairwise comparisons of the 30 countries is taken and set at zero. The individual countries are then ordered in terms of their deviation from this average according to the average of the UNIDIFF parameters returned from each of the pairwise comparisons in which they were themselves involved. Negative deviations indicate that the odds ratios capturing the association between class origins and destinations in a country's mobility table are uniformly lower than the average - i.e. there is greater social fluidity within its class structure; while, conversely, positive deviations indicate that the odds ratios are uniformly higher than the average - i.e. there is less social fluidity.

However, while Figure 2 gives a useful summary of our findings, it is misleading insofar as it might be taken to imply an entirely continuous variation in levels of relative rates across the countries covered. More detailed analyses actually reveal that many of the differences in fluidity among countries that are suggested in Figure 1 are not statistically significant; and that a better understanding of cross-country variation may in fact be gained if countries are seen as falling into a number of groups such that, so far as overall levels of fluidity are concerned, within-group differences tend to be less than between-group differences. We would identify six such groups as follows: a set of three comparatively 'high fluidity' groups of countries lying below or just on the average line of Figure 2 and a set of three 'low fluidity' groups of countries lying above this line. 
FIGURE 2: Country differences in relative rates of social mobility, men aged 25-64

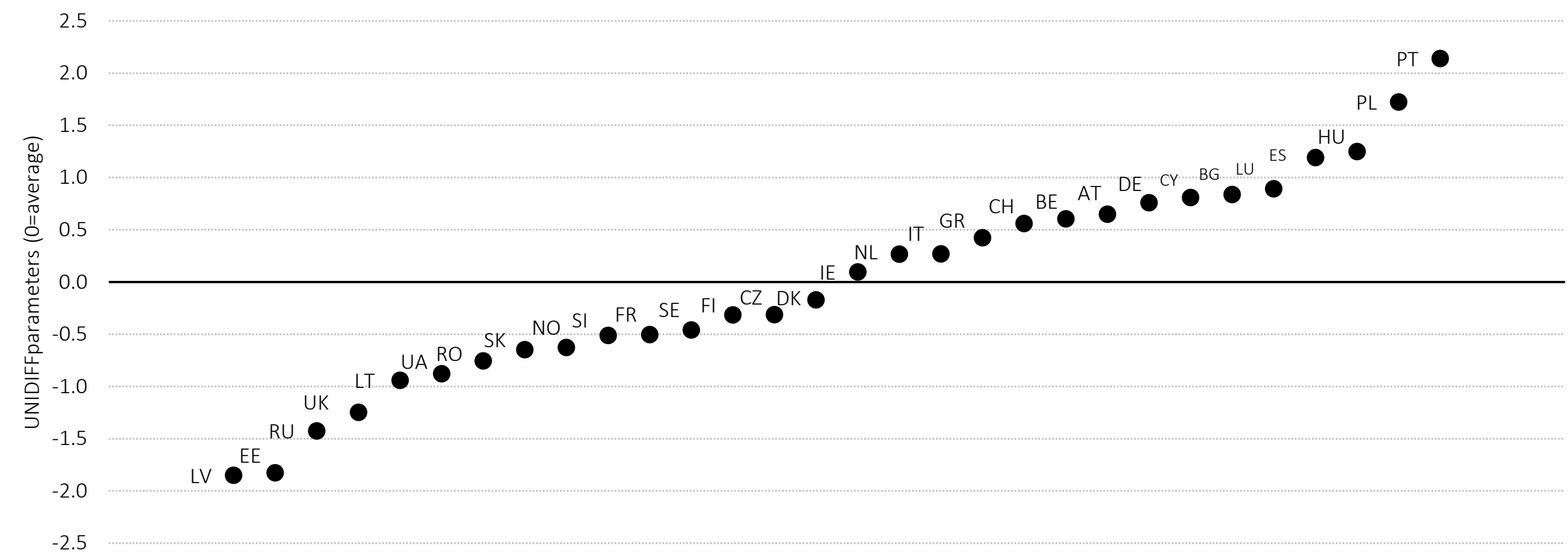

Note:

LV: Latvia; EE: Estonia; RU: Russia; UK: United Kingdom; LT: Lithuania; UA: Ukraine; RO: Romania; SK: Slovakia; NO: Norway; SI: Slovenia; FR: France; SE: Sweden; FI: Finland; CZ: Czech Republic; DK: Denmark; IE: Ireland; NL: Netherlands; IT: Italy; GR: Greece; CH: Switzerland; BE: Belgium; AT: Austria; DE: Germany; CY: Cyprus; BG: Bulgaria; LU: Luxembourg; ES: Spain; HU: Hungary; PL: Poland; PT: Portugal 
Groups in the high fluidity set:

(1) Five former countries of the USSR, Estonia, Latvia, Lithuania, Russia and Ukraine (former USSR);

(2) Four other post-communist countries, the Czech Republic, Slovakia, Slovenia and Romania (other post-communist -1);

(3) Four Nordic countries, Denmark, Finland, Norway and Sweden together with three West European countries, France, Ireland and the UK (West-Nordic).

Groups in the low fluidity set:

(1) Six contiguous West-Central European countries, Austria, Belgium, Germany, Luxembourg, the Netherlands and Switzerland (West-Central);

(2) Five Southern European countries, Cyprus, Greece, Italy, Portugal and Spain (Southern);

(3) Three further post-communist countries, Bulgaria, Hungary and Poland (other postcommunist - 2).

The main substance of the analyses on which we here draw is presented in Figure 3. This takes the form of a half-matrix which shows the results of fitting both the CA and the UNIDIFF models to all pairs of our 30 countries. The countries are placed in the groups indicated above but otherwise as far as possible according to the ordering of Figure 2. Hollow circles indicate that the CA model gives an adequate fit to the two mobility tables in question at the $p>0.05$ level; and hollow triangles indicate that while the CA model does not fit the tables, the UNIDIFF model does not improve on it: i.e. in these cases there are significant differences in the pattern of relative rates of class mobility, but these do not result in one country being systematically more fluid than the other. Filled circles then indicate that the UNIDIFF model both improves significantly on the CA model and gives an adequate fit to the two tables, with the country on 
the $B$ axis having lower fluidity than that on the $A$ axis; and filled triangles indicate that although the UNIDIFF model significantly improves on the CA model, it still does not fit adequately: i.e. as well as the country on the B axis being less fluid than that on the A axis (or vice versa with the two half-filled triangles) there are further differences in their mobility regimes. ${ }^{7}$

${ }^{7}$ In considering the results presented in Figure 3, it has to be kept in mind that sample sizes vary a good deal across countries - from 4300 in Germany down to 709 in Italy. Thus, there are differences in statistical power that make it easier to detect deviations from our models in some comparisons than in others; and for this and other reasons some apparent inconsistencies arise of the kind that while, say, the $C A$ model is shown as fitting for countries $X$ and $Y$ and also for countries $Y$ and $Z$, it does not fit for countries $X$ and $Z$. As a robustness check, we have for all countries for which the sample size is less than 1000 (Lithuania, Latvia, Romania and Luxembourg as well as Italy) re-run our models with their sample size scaled up to be the same as that of the comparator country. While in some cases, as might be expected, both the CA and UNIDIFF models no longer give acceptable fits, the overall pattern of results shown in Figure 3 is changed only that in these cases hollow triangles replace hollow circles or filled triangles, filled circles. 
FIGURE 3: Results of fitting the CA and the UNIDIFF models to each pair of countries, men aged 25-64 (a)

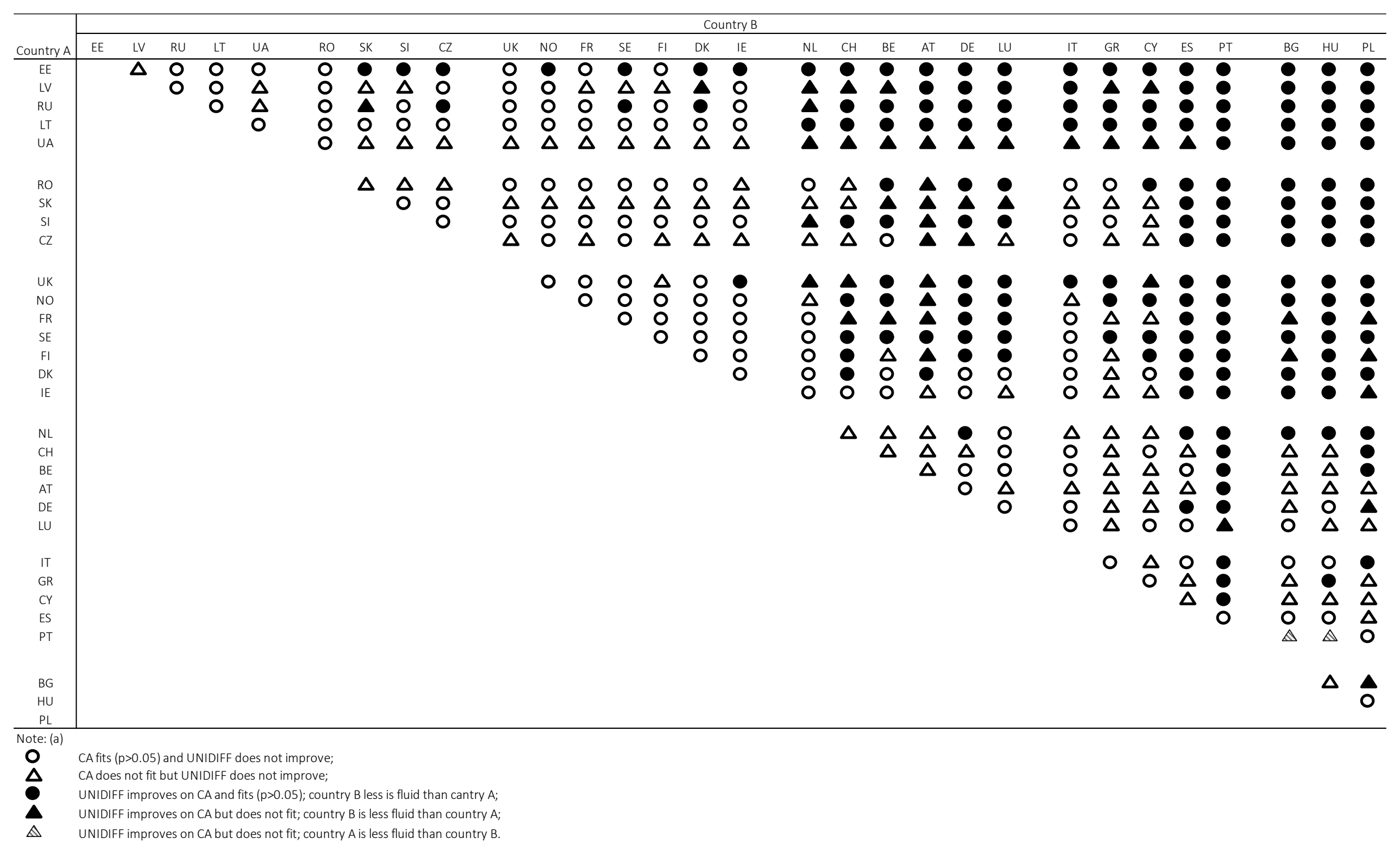


If one focuses on those sections of the half-matrix that fall along the diagonal, where results are shown for the pairwise comparisons of countries in the same group, it can be seen that hollow circles or triangles predominate: i.e. within each of the six groups what might be called the endogenous mobility regimes of the countries comprised tend to have a high degree of commonality, with such differences as arise not being ones indicating greater or less fluidity overall. The most obvious exception is that in the Southern group Portugal appears as having still lower fluidity than the other countries included, apart from Spain.

Hollow circles or triangles are also for the most part found in the sections of the half-matrix towards the top-left and bottom-right corners where the comparisons involved are between pairs of countries in different groups but groups within either the high fluidity or low fluidity set. That is to say, there is also a quite high degree of similarity in mobility regimes across the countries in each of these sets. In the high fluidity set, only Estonia and to a lesser degree Russia stand out as having yet higher fluidity than most countries in both the other post-communist and the West-Nordic groups, while Denmark appears as less fluid than Latvia and Russia as well as Estonia within the post-USSR group. In the low fluidity set, Portugal, again, and to a lesser degree Poland are the outliers, the former showing lower fluidity than all of the countries in the West-Central group, and the latter lower fluidity than most of the countries in this group.

In contrast, in the nine sections of the half-matrix towards the upper right corner, where the comparisons involved are between one country from a group in the high fluidity set and another from a group in the low fluidity set, filled circles and triangles are by far most commonly found - in almost four-fifths of all entries. The exceptions largely arise with a small number of countries that could be regarded as in some respects borderline cases. Thus, Ireland appears as borderline between the West-Nordic group in which it is placed in the high fluidity 
set and the West-Central and Southern groups in the low fluidity set. And the Netherlands in the West-Central group and Greece and possibly Italy in the Southern group, while clearly less fluid than the countries in the post-USSR group are not differentiated in their fluidity from most of the countries in the other two groups in the high fluidity set. ${ }^{8}$

However, despite the existence of these borderline cases, Figure 3 would still suggest that it is more revealing to view differences in relative rates of class mobility among European countries as having a segmented rather than an entirely continuous form. And if this is accepted, it is relevant to note that, as shown in Table 2, there is no strong association between the countries in our low and high fluidity sets and economic inequality as measured by Gini coefficients - for equivalised disposable household income after taxes and transfers (Russia and the Ukraine being excluded because no comparable Ginis are available). Thus, while within the high fluidity set the Nordic countries do all have low Ginis, as also do most of the post-communist countries other than those formerly part of the USSR, the post-USSR countries themselves have high Ginis, as also does the UK, with France and Ireland being in the intermediate range. And while among the low fluidity groups Greece and Portugal have high Ginis, as also do Bulgaria and Poland, though not Hungary, the Ginis for the countries in the West-Central group are all in the low or intermediate range. When mobility is considered in terms of class, it would then appear that the relation with inequality will need to be understood as more complex than in the scarcely successful - attempt expressed in the GGC. We go on to suggest a theoretically grounded interpretation of our empirical findings that aims to accommodate this complexity.

\footnotetext{
8 Italy has to be regarded as an especially problematic and uncertain case. Not only is the sample size unusually small, but one might well expect marked regional differences.
} 
TABLE 2: Income inequality and relative class mobility

\begin{tabular}{lll}
\hline Level of income inequality & \multicolumn{2}{c}{ Level of relative class mobility } \\
\hline $\begin{array}{l}\text { Average Gini coefficient in } \\
\text { 2002-2010 }\end{array}$ & & \multicolumn{1}{c}{ Low } \\
Low (23-27) & CZ, SI, SK; DK, FI, NO, SE & AT, BE, LU, NL; HU \\
Intermediate (28-32) & FR, IE & CH, DE; CY, ES, IT \\
High (33-37) & EE, LT, LV; RO; UK & GR, PT; BG, PL \\
\hline
\end{tabular}

Note:

(a): Gini coefficients for equivalised disposable household income after taxes and transfers and are taken from EUROSTAT.

\section{Theory and Interpretation}

In the light of some early data from national studies of intergenerational social mobility, Featherman, Jones and Hauser (1975: 340) advanced a bold hypothesis: that in all societies with a market economy and a nuclear family system the pattern and level of their relative rates would be 'basically the same'. Erikson and Goldthorpe (1992: ch. 4), with more extensive and more comparable data at their disposal, suggested qualifying the 'FJH hypothesis', at least as regards class mobility, in two main ways: first, by replacing the idea of a basic similarity in relative rates with that of a 'core pattern', around which some amount of variation of a nationally specific kind could occur; and second, by noting that a potent source of such variation could be the use of state power in order to regulate and modify mobility processes. The theoretical basis on which we would interpret the results that we have reported represents a further development of these ideas. 
What we propose is that in all societies with a capitalist market economy, a nuclear family system and a liberal-democratic polity, a limit exists to the extent to which relative rates of class mobility can be brought towards equality or, in other words, to the extent to which the net association between the class positions of parents and their children can be reduced. This is so because of the capacity of parents in more advantaged class positions to draw on their superior resources to the extent necessary in order to maintain their children's greater chances of success in educational systems and labour markets, relative to those of children of parents in less advantaged class positions. Thus, in liberal democracies, policy interventions aimed at creating a greater equality of opportunity must, beyond a certain point, face mounting political difficulties. That is, insofar as these interventions are aimed either at restricting parents' abilities - and what might indeed be seen as their rights - to use such resources as they possess to 'do the best they can' for their children; or at significantly reducing the overall level of inequality that exists in such resources - inequalities in economic resources, including income, but also inequalities in socio-cultural and specifically educational resources. And these latter inequalities have to be recognised as being far less open than economic inequalities to acceptable political modification in that their expression in relation to children's development could in fact be often regarded as constitutive of family life. It would, for example, be scarcely feasible - let alone desirable - to ban the reading of bed-time stories or supper-table debates (cf. Brighouse and Swift, 2014).

Given that a limit of the kind in question exists, it is then possible to understand variation in relative rates of class mobility in terms of how close countries are to it and whether they are moving towards or away from it. But rather than it being possible to relate variation in this regard to any one underlying factor, it is necessary to see different forms of inequality as 
impacting on the degree of fluidity within countries' class structures in quite differing ways. We now view our results in this perspective, and also in the light of the extensive literature that has built up on levels and trends of relative rates of class mobility in a European context.

We consider, first of all, countries in the West-Nordic group within the high fluidity set. These countries we would regard as being not far removed from our proposed limit on equality in relative rates, and as ones in which we would not therefore expect any further increases in social fluidity of a substantial kind to occur. Or, at all events, attempts in this direction would have to be ones made in the face of increasingly strong political resistance. In the case of the Nordic countries themselves there is in fact evidence that the rising social fluidity observed in studies made in the later twentieth century reflected the distinctive experience of particular birth cohorts and has not continued, so that, through processes of cohort replacement, relative rates are tending to stabilise (for Sweden, see Jonsson, 2004, Breen and Jonsson, 2007; for Finland, Erola, 2009). Similarly, increases in fluidity in France, earlier driven in part by the decline of the agricultural sector, in which a high propensity for immobility prevailed, would now appear to be levelling out, if not to have ceased (Vallet, 2014). And in the cases of the UK - or at any rate Britain - and also Ireland relative rates have shown only slight, if any, change towards greater fluidity from the mid-twentieth century onwards (for Britain, see Bukodi et al. 2015, Buscha and Sturgis, 2018; for Ireland, Layte and Whelan, 2004).

With both of the two groups of post-communist countries that are also included in our high fluidity set, we would, however, see a quite different situation. These countries, we would argue, are ones in which, under communist regimes, it was possible to achieve a level of social fluidity that went beyond the limit that we would envisage for capitalist liberal democracies but countries in which fluidity is now falling back to a level somewhat below this limit following 
their transition to market economies and to some form of democracy. In mobility research carried out before the break-up of the Soviet bloc those communist countries of East-Central Europe for which sufficiently good data were available were found to be generally more fluid than most of those in Western Europe (Erikson and Goldthorpe, 1992: chs. 4 and 5; Marshall, Swift and Roberts, 1997: ch. 4; Titma, Tuma and Roosma, 2003). This appeared to be the result of close state control over educational systems, aimed directly at reducing social inequalities in attainment - to the point in some cases of negative discrimination against children of supposed 'bourgeois' origins - together with the tight linkages that were imposed between qualifications and level and type of employment. Further, the raising of the earnings of manual workers so as often to equal, or even exceed, those of the 'intelligentsia', meant that mobility was, in any event, a 'low stakes game': the incentives to achieve upward mobility or to avoid downward were alike reduced. ${ }^{9}$

However, in mobility research subsequently carried out in post-communist countries it has been quite generally found that fluidity within the class structure is in decline (see for Russia, Gerber and Hout, 2004; for Hungary, Bukodi and Goldthorpe, 2010; for Estonia, Saar 2010; and for an important comparative analysis, Jackson and Evans, 2017). Factors frequently cited as underlying this decline include the increasing stratification and 'commodification' of public educational systems, the growth of private education, widening economic inequality resulting from rising earnings returns to education, the dismantling of egalitarian social policies, and

\footnotetext{
${ }^{9}$ Special privileges were of course enjoyed by the nomenklatura, including ones that helped them maintain their children in advantaged positions, but the consequences of this can easily be exaggerated at least so far as 'mass' rather than 'elite' mobility is concerned (Titma, Tuma and Roosma, 2003). The most detailed account of the attempt to design an egalitarian society under communism is that provided by Szelényi (1998) for Hungary, and it is for Hungary that the increase in fluidity from the precommunist to the communist era can most closely be traced (Andorka, 1990).
} 
intensifying competition for access to higher level positions often involving the exploitation of more or less exclusive social networks. While, then, the post-communist countries in our high fluidity set appear together with the West-Nordic countries at close to what we would take to be the limit on increased fluidity, they are not to be understood as ones that are pushing this limit. Although transitional economic and social turbulence may, especially in the former USSR countries, have helped to maintain intergenerational fluidity through creating greater uncertainty in class returns to education and creating increased intragenerational mobility (see e.g. Titma and Roots, 2006; Saar and Unt, 2011; Bühler and Konietzka, 2011), post-communist countries are to be regarded as in general moving away from the limit; and a continuation of this movement has to be regarded as very probable.

This last point is underlined when we turn to our low fluidity set and consider the further group of post-communist countries, Bulgaria, Hungary and Poland, that is included. While we have little knowledge of mobility in Bulgaria during the communist era, Hungary and Poland could certainly be ranked at this time among European countries with the highest levels of social fluidity; but, having become by the start of the twenty-first century perhaps the two most economically 'liberalised' post-communists societies, they now appear at the opposite end of the European range. Significant differences are, however, evident in features of their transitions that can be associated with declining fluidity.

In Hungary the transition was accompanied by 'a fundamental change in the ... school system' (Keller and Robert, 2016), which in effect re-established the German tradition of stratified secondary education with early selection for Gymnasium places, while some degree of privatisation also occurred, especially in the tertiary sector. At the same time as social inequalities in educational attainment were thus widened (Bukodi and Robert, 2011), class 
returns to education increased, and, if anything, more so than earnings returns (Bukodi, 2010). What we then find from more detailed analyses of our ESS data is that in the Hungarian case an important part is played in the low fluidity that now exists by barriers to mobility of a longrange kind: that is, from origins in the broadly defined wage-earning working class - ESeC Classes 6 and 7 - to destinations in salaried managerial and professional positions - ESeC classes 1 and $2 .^{10}$

In Poland, in some contrast, the most significant change in the educational system associated with the transition was the very extensive privatisation of the tertiary sector - the number of private institutions of higher education quickly rising to around double that of public institutions (Baranowska, 2008: 279), and at the same time returns to higher education in terms of both class and income increased quite dramatically (Domanski, 2011). In addition, a further distinctive feature of the Polish transition has been the rise and stabilisation of the proportion of the workforce in self-employment - at something over 20 per cent (Baranowska, 2008: 284). Our more detailed analyses then reveal that a major factor in low fluidity in Poland is a high propensity for immobility, and especially in ESeC Classes 1 and 4: that is, in the classes that include higher level self-employed professionals, employers and other 'independents',

\footnotetext{
${ }^{10}$ These analyses are based on a topological model of the pattern of social fluidity developed in the British case (Bukodi, Kuha and Goldthorpe, 2017) but which proves to have much wider applicability. Further details of the analyses are available on request. It is relevant to note that the decrease in fluidity in Hungary did actually begin before the end of communism, following on the 'marketisation' introduced under the rubric of the 'New Economic Mechanism' at the end of the 1970s (see Róbert and Bukodi, 2004).
} 
and in which therefore the possibility exists of the direct intergenerational transmission of practices or businesses as 'going concerns' or of amounts of capital. ${ }^{11}$

The Bulgarian case, in which the transition was an especially difficult one, is different again. GDP and fiscal revenues declined well into the 1990s, with very adverse consequences for the educational system. Real expenditure on education did not return to its 1990 level until the early 2000s. Over this period, educational standards among children from less advantaged backgrounds actually fell, and it has been shown (Hertz, Meurs and Selcuk, 2009) that a marked strengthening occurred in the association between children's level of educational attainment and that of their parents: i.e. intergenerational educational mobility significantly declined. In our more detailed analyses, we find that low fluidity in Bulgaria is expressed both in comparatively high barriers to long-range mobility and in generally high propensities for class immobility, although especially among the higher managers and professionals of ESeC Class 1.

Moving on now to the Southern countries in our low fluidity set, it is here, despite the borderline cases we previously noted, that we find perhaps the most straightforward relation between inequality and mobility. As earlier observed, these are countries with high economic inequality, as indicated by Ginis for net disposable household income of around 30 or higher; and, further, ones with high educational inequality as indicated by Ginis for years of education (Ziesemer, 2016) ranging from 25 for Italy to around 40 for Portugal and Spain - in comparison with, say, with such Ginis for countries in the West-Nordic group which in no case exceed 20. In addition, the Southern countries are all ones in which comparatively large numbers of men

\footnotetext{
${ }^{11}$ ESeC Class 4 is notably large in the marginal distributions of our Polish mobility table. Poland was, of course, distinctive within the Soviet bloc in that agriculture was never collectivised and small scale enterprises outside of agriculture, especially in the services sector, were more widely permitted than elsewhere.
} 
are found in ESeC Class 4, that of small proprietors and self-employed workers, due in part to still relatively large agricultural sectors but also to the prevalence of small-scale enterprises in both manufacturing and services. In these countries, therefore, the role of education in weakening the association between class origins and destinations would appear especially limited and, correspondingly, the 'direct effect' of origins on destinations - i.e. that not mediated via education - has been shown, where relevant analyses can be made, to be especially strong (Ballarino and Bernardi, 2016: Figure 16.1). Our own more detailed analyses show that low fluidity in these countries is associated with a generally strong propensity for class immobility and, in particular, within ESeC Class $4 .^{12}$

However, what may also be noted is that in those Southern European cases where relevant evidence is available - Italy and Spain - social fluidity would appear to be on the increase, even if, so far at least as men are concerned, only to a rather modest extent (for Italy, see Pisati and Schizzerotto, 2004, Schizzerotto, 2017; for Spain, Gil-Hernández, Marqués Perales and Facelli, 2017). In the perspective we would adopt, these countries, being some way off the limit on rising fluidity that we envisage, can at all events be seen as ones that have the clear possibility of moving closer to it.

Finally, we come to our West-Central group of countries within the low fluidity set. These countries stand in contrast to those in the Southern group in that they can all be regarded as advanced industrial societies with high standards of living and, moreover, with levels of economic inequality little different from those of countries in the West-Nordic group. The main source of the lower fluidity that the West-Central countries display lies, we would suggest, in

\footnotetext{
12 These analyses cannot be extended to Italy because of the small sample size previously noted.
} 
the fact that, in comparison with those of the West-Nordic group, they have somewhat greater social class inequalities in educational attainment and also stronger linkages between educational qualifications and class positions. In other words, they are distinctively 'credentialist' societies in which inequalities in educational attainment translate very directly into inequalities in class mobility chances. ${ }^{13}$

This view is supported by research into the extent of changes in fluidity in West-Central countries over recent decades. Where some change has occurred, this has been, as in the Southern countries, in the direction of greater fluidity; and such change would then appear to be closely associated with the reduction of educational inequalities. Such a reduction has clearly occurred in the Netherlands (Breen et al., 2009), while at the same time fluidity within the class structure has increased (Ganzeboom and Luijkx, 2004,a,b) - to the point in fact, that the Netherlands, as was earlier recognised, could be regarded as a borderline case between the West-Central and the West-Nordic groups. A similar pattern of change is quite possibly to be found in Germany (Breen et al., 2009; Müller and Pollak, 2004, 2015) but it has to be noted that all analyses so far made relate to the former West Germany and may not apply unqualified to Germany after reunification (cf. Gebel, 2011). Switzerland could, however, be taken as standing in quite clear contrast with the Netherlands. The available evidence indicates little or no change in educational inequality (Buchman and Charles, 1993), while fluidity within the class structure has remained essentially constant across cohorts extending back to those born in the inter-war years (Falcon, 2012). In other words, in highly credentialist societies, it is the

\footnotetext{
${ }^{13}$ The strongest evidence in this latter regard is for Germany. See, for example, Klein (2011) and Grätz and Pollak (2016). For Britain as a contrasting case, where education is to a clearly lesser degree 'class destiny', see Bukodi et al. (2016).
} 
reduction specifically of educational inequalities - a weakening of the association between social origins and educational attainment - that would appear key to the equalisation of relative mobility chances.

In Figure 4 we sum up in graphical form our interpretations of the differing fluidity trajectories that have been followed by our groups of European nations in relation to the limit we have proposed on the extent to which relative rates of class mobility can be equalised. 
FIGURE 4: Fluidity trajectories in relation to proposed limit for countries with a capitalist market economy, a nuclear family system and a liberal democratic polity ${ }^{(a)}$

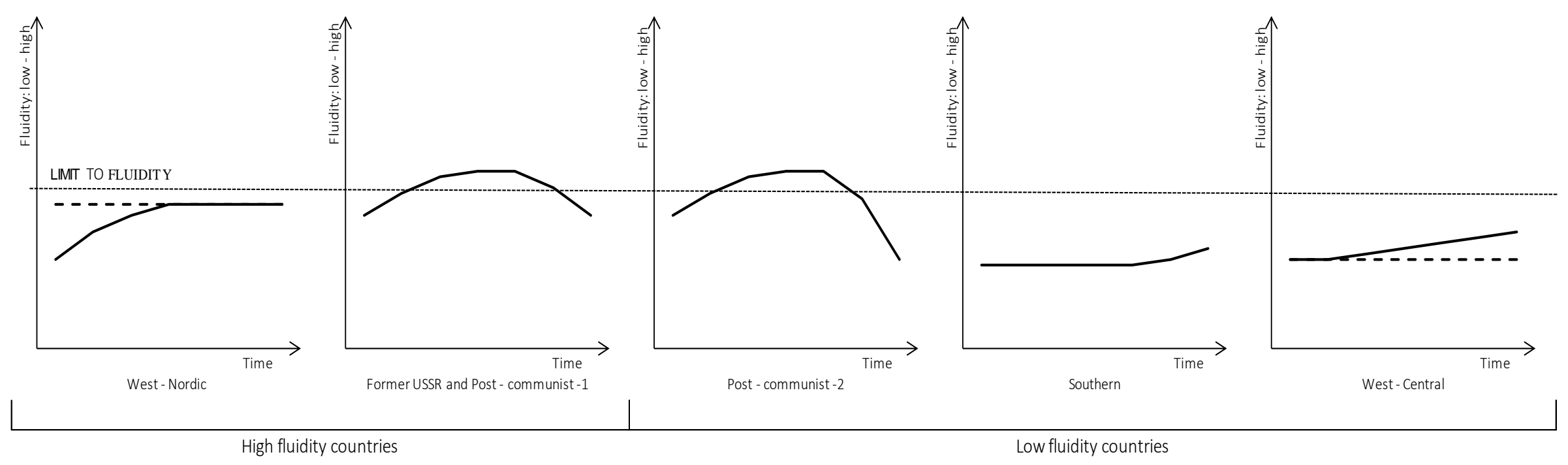

Note (a):

$\begin{array}{ll}- & \text { main trajectory } \\ --- & \text { alternative trajectory }\end{array}$




\section{Conclusions}

In this paper we have started from a position that would be shared by most sociologists: i.e. that the relation between inequality and mobility has to be understood as an inverse one, at least in the sense that, beyond some point, inequality of condition must compromise equality of opportunity. However, we have argued that the attempt to relate inequality to mobility purely in terms of income, in the way that is attempted via the GGC, is not convincing on either empirical or theoretical grounds. The robustness of the GGC is open to serious doubt; and there seems little basis for the assumption that income inequality is the only, or even the primary, factor conditioning income mobility.

We have gone on to maintain that treating mobility in terms of social class, rather than income, enables a more comprehensive account to be given of the intergenerational transmission of economic advantage and disadvantage; and we have sought to show, exploiting a newly constructed European dataset, that if mobility is treated in this way, a fuller, albeit more complex, understanding of the relation of mobility to inequality can be gained. The results of our analyses indicate that European nations are best seen not as displaying entirely continuous variation in the degree of equality in their relative rates - or that is, in the degree of social fluidity prevailing within their class structures - but rather as falling into a number of comparatively high and low fluidity groups.

We have then suggested that an interpretation of these results can be provided by starting out from the supposition that, within societies with a capitalist market economy, a nuclear family system and a liberal democratic polity, a limit exists to the extent to which relative rates of class mobility can be brought towards equality - but with due recognition being given to the 
fact that how far countries approximate or fall short of this limit and whether they are moving towards or away from it will depend on the impact of social inequalities of varying kinds, as reflected in the differing resources that parents have available in furthering their children's life-chances. In short, while the relation between inequality and mobility can be regarded as, in general, an inverse one, the way in which this relation actually works out cannot be captured in any one-dimensional linear fashion; it is a complex and differentiated one, an understanding of which calls for close attention to the specifics of particular countries and to the courses that their economic and political histories have followed. 


\section{References}

Andorka, R. (1990): 'Half a century of trends in social mobility in Hungary' in J. J. Peschar ed., Social Reproduction in Eastern and Western Europe. Nijmegen: Institute for Applied Social Science.

Ballarino, G. and Bernardi, F. (2016): 'The intergenerational transmission of inequality and education in fourteen countries: a comparison' in F. Bernardi and G. Ballarino eds., Education, Occupation and Social Origin. Cheltenham: Edward Elgar.

Baranowska, A. (2008): 'Poland' in I. Kogan, M. Gebel and C. Noelke eds., Europe Enlarged. Bristol: Policy Press.

Björklund, A. and Jäntti, M. (2009): 'Intergenerational income mobility and the role of family background' in W. Salverda, B. Nolan and T. M. Smeeding eds., The Oxford Handbook of Economic Inequality. Oxford: Oxford University Press.

Bratsberg, B. et al. (2007): 'Nonlinearities in intergenerational earnings mobility: consequences for cross-country comparisons', Economic Journal, 117: C72-C91.

Breen, R. and Jonsson, J. O. (2007) 'Explaining change in social fluidity: educational equalization and educational expansion in twentieth century Sweden', American Journal of Sociology, 112: 1775-1810.

Breen, R., Luijkx, R., Müller, W. and Pollak, R. (2009): 'Nonpersistent inequality in educational attainment: evidence from eight European countries', American Journal of Sociology, 114: 1475-1521.

Brighouse, H. and Swift, A. (2014): Family Values. Princeton: Princeton University Press.

Buchman, M. and Charles, M. (1993): 'The lifelong shadow: social origins and educational opportunity in Switzerland' in Y. Shavit and H.-P. Blossfeld eds., Persistent Inequality: Changing Educational Attainment in Thirteen Countries. Boulder: Westview Press.

Bühler, C. and Konietzka, D. (2011): 'Institutional change and the transition from school to work in Russia' in I. Kogan, C. Noelke and M. Gebel eds., Making the Transition: Education and Labor Market Entry in Central and Eastern Europe. Stanford: Stanford University Press.

Buis, M. L. (2013): 'The composition of family background: the influence of the economic and cultural resources of both parents on the offsprings' educational attainment in the Netherlands between 1939 and 1991', European Sociological Review, 29: 593-602. 
Bukodi, E. (2010): 'Educational expansion and social class returns to tertiary qualifications in post-communist countries' in J. Dronkers ed., Quality and Inequality in Education. Dordrecht: Springer.

Bukodi. E. and Goldthorpe, J. H. (2010): 'Market versus meritocracy: Hungary as a critical case', European Sociological Review, 26: 655-74.

Bukodi, E. and Róbert, P. (2011): 'Education and labor market in transition: the case of Hungary' in I. Kogan, C. Noelke and M. Gebel eds., Making the Transition: Education and Labor Market Entry in Central and Eastern Europe. Stanford: Stanford University Press.

Bukodi, E. and Goldthorpe, J. H. (2018): Social Mobility and Education in Britain: Research, Policy and Politics. Cambridge: Cambridge University Press.

Bukodi, E., Erikson, R. and Goldthorpe, J.H. (2014): 'The effects of social origins and cognitive ability on educational attainment: evidence from Britain and Sweden', Acta Sociologica, 57: 293-310.

Bukodi, E, Goldthorpe, J. H. and Kuha, J. (2017): 'The pattern of social fluidity within the British class structure: a topological model', Journal of the Royal Statistical Society, Series A, 180: 841862.

Bukodi, E., Goldthorpe, J. H., Waller, L. and Kuha, J. (2015): 'The mobility problem in Britain: new findings from the analysis of birth cohort data', British Journal of Sociology, 66: 93-117.

Bukodi, E.,Goldthorpe, J. H., Halpin, B. and Waller, L. (2016): 'Is education now class destiny? Class histories across three British birth cohorts', European Sociological Review, 32: 835-49.

Buscha, F. and Sturgis, P. (2018): 'Declining social mobility? Evidence from five linked censuses in England and Wales, 1971-2011', British Journal of Sociology, 69: 154-182.

Chetty, R. et al. (2014): 'Is the United States still a land of opportunity? Recent trends in intergenerational mobility', American Economic Review, 104: 141-147.

Corak, M. (2013): 'Income equality, equality of opportunity, and intergenerational mobility', Journal of Economic Perspectives, 27: 79-102.

Corak, M. (2015): 'Economic theory and practical lessons for measuring equal opportunities', Memorandum prepared for the High Level Expert Group on the Measurement of Economic Performance and Social Progress, OECD.

Corak, M., Lindquist, M. J. and Mazumder, B. (2014): 'A comparison of upward and downward intergenerational mobility in Canada, Sweden and the United States', Labour Economics, 30: 185-200. 
Davis, J. and Mazumder, B. (2017): 'The decline in intergenerational mobility after 1980', Federal Reserve Bank of Chicago, Working Paper 2017-05.

Domanski, H. (2011): 'Rise of meritocracy in Poland: 1982-2008', European Sociological Review, 27: 400-411.

Erikson, R. (1984): 'Social class of men, women and families', Sociology, 18: 500-514.

Erikson, R. (2016): 'Intergenerational associations of stratification dimensions - do they change and, if so, in concert?' ESRC Annual Conference, Oxford.

Erikson, R. and Goldthorpe, J. H. (1992): The Constant Flux. Clarendon Press: Oxford.

Erola, J. (2009): 'Social mobility and education of Finnish cohorts born 1936-75: succeeding while failing in equality of opportunity', Acta Sociologica, 52: 307-327.

Falcon, J. (2012): 'Temporal trends in intergenerational social mobility in Switzerland: a cohort study of men and women born between 1912 and 1974', Swiss Journal of Sociology, 38: 153176.

Featherman, D., Jones, F. L. and Hauser, R.M. (1975): 'Assumptions of social mobility research in the US: the case of occupational status', Social Science Research, 4: 329-360.

Ganzeboom, H. G. B. and Luijkx, R. (2004a): 'Recent trends in intergenerational occupational class reproduction in the Netherlands' in R. Breen ed., Social Mobility in Europe. Oxford: Oxford University Press.

Ganzeboom, H. G. B. and Luijkx, R. (2004b): 'More recent trends in intergenerational occupational class reproduction in the Netherlands 1970-2004: evidence from an expanded database', Netherlands Journal of Social Science, 40: 114-142.

Gebel, M. (2011): 'Hard times for the less educated: education and labour market entry in East Germany after reunification' in I. Kogan, C. Noelke and M. Gebel eds., Making the Transition: Education and Labor Market Entry in Central and Eastern Europe. Stanford: Stanford University Press.

Gerber, T. P. and Hout, M. (2004): 'Tightening up: declining class mobility during Russia's market transition', American Sociological Review, 69: 677-703.

Gill-Hernandèz, C. J., Marqués-Perales, I. and Fachelli, S. (2017): 'Intergenerational social mobility in Spain between 1956 and 2011: the role of educational expansion and economic modernisation in a late industrialised society', Research in Social Stratification and Mobility, 51 : 14-27.

Goldthorpe, J. H. (2013): 'Understanding - and misunderstanding - social mobility: the entry of 
the economists, the confusion of politicians and the limits of educational policy', Journal of Social Policy, 42: 431-450.

Grätz, M. and Pollak, R. (2016): 'Legacies of the past: social origin, educational attainment and labour market outcomes in Germany' in F. Bernhardi and G. Ballarino eds., Education, Occupation and Social Origin. Cheltenham: Edward Elgar.

Hertz, T., Meurs, M. and Selcuk, S. (2009): 'The decline in intergenerational mobility in postsocialism: evidence from the Bulgarian case', World Development, 37: 739-752.

Hout, M. (2018): 'American occupational status reflects the status of both of their parents', Proceedings of the National Academy of Sciences, www.pnas.org/cgi/doi/10.1073/ pnas. 1802508115.

Jackson, M. and Evans, G. (2017): 'Rebuilding walls: market transition and social mobility in the post-socialist societies of Europe', Sociological Science, 4: 54-79.

Jaeger, M. M. (2007) 'Educational mobility across three generations: the changing impact of parental social class, economic, cultural and social capital', European Societies, 9: 527-550.

Jäntti, M. and Jenkins, S. (2015): 'Income Mobility' in A. B. Atkinson and F. Bourguignon eds. Handbook of Income Distribution, vol. 2. Amsterdam: North-Holland Elsevier.

Jerrim, J., Choi, A. and Simancas, R. (2016): 'Two-sample, two-stage least squares (TSTSLS) estimates of earnings mobility: how consistent are they?', Survey Research Methods, 10: 85102.

Jonsson, J. O. (2004): 'Equality at a halt? Social mobility in Sweden, 1976-99' in R. Breen ed., Social Mobility in Europe. Oxford: Oxford University Press.

Keller, T. and Róbert, P. (2016): 'Inequality in educational returns in Hungary' in F. Bernhardi and G. Ballarino eds., Education, Occupation and Social Origin. Cheltenham: Edward Elgar.

Klein, M. (2011): 'Trends in the association between educational attainment and class destinations in West Germany: looking inside the service class', Research in Social Stratification and Mobility, 29: 427-444.

Krueger, A. (2012): 'The rise and consequences of inequality in the United States'. Speech at the Center for American Progress, Washington DC.

Layte, R. and Whelan, C. T. (2004): 'Class transformation and trends in social fluidity in the Republic of Ireland 1973-94' in R. Breen ed., Social Mobility in Europe. Oxford: Oxford University Press. 
McGovern, P., Hill, S., Mills, C. and White, M. (2007): Market, Class and Employment. Oxford: Oxford University Press.

Marshall, G., Swift, A, and Roberts, S. (1997): Against the Odds. Oxford: Oxford University Press. Müller, W. and Pollak, R. (2015): 'Bildung und Soziale Mobilität in Deutschland', AstA Wirtschafts- und Sozialstatistsches Archiv, 9: 5-26.

OECD (2018): A Broken Social Elevator? How to Promote Social Mobility. Paris: OECD Publishing.

Pisati, M. and Schizzerotto, A. (2004): 'The Italian mobility regime: 1985-97' in R. Breen ed., Social Mobility in Europe. Oxford: Oxford University Press.

Róbert, P. and Bukodi, E. (2004): 'Changes in intergenerational class mobility in Hungary, 19732000' in R. Breen ed., Social Mobility in Europe. Oxford: Oxford University Press.

Rose, D. and Harrison, E. (2010): Social Class in Europe: An Introduction to the European SocioEconomic Classification. London: Routledge.

Saar, E. (2010): 'Changes in intergenerational mobility and educational inequality in Estonia: comparative analyses of cohorts born between 1930 and 1974', European Sociological Review, 26: 367-383.

Saar, M. and Unt, M. (2011): 'Education and Labor Market Entry in Estonia' in I. Kogan, C. Noelke and M. Gebel eds., Making the Transition: Education and Labor Market Entry in Central and Eastern Europe. Stanford: Stanford University Press.

Schizzerotto, A. (2017): 'Long-Run Transformations in Mobility Processes in Italy', Isitituto Carlo Cattaneo Conference on Trends in Inequality, Bologna.

Szelényi, S. (1998): Equality by Design: the Grand Experiment in Destratification in Socialist Hungary. Stanford: Stanford University Press.

Titma, M. and Roots, A. (2006): 'Intragenerational mobility in successor states of the USSR', European Societies, 8: 493-526.

Titma, M., Tuma, N. and Roosma, K. (2003): 'Education as a factor in intergenerational mobility in Soviet society', European Sociological Review, 19: 281-297.

Vallet, L. A. (2014): 'Mobilité observée et fluidité sociale en France de 1977 à 2003', Idées economique et sociales, 175: 6-17.

Winship, S. (2017): Economic Mobility: A State-of-the-Art Primer. Washington: Archbridge Institute. 
Xie, Y. (1992) 'The log-multiplicative layer effect model for comparing mobility tables', American Sociological Review, 57: 380-395.

Ziesemer, T. (2016): 'Gini coefficients for education for 146 countries, 1950-2010', Bulletin of Applied Economics, 3: 1-8. 